\title{
MUDANÇAS NO CAMPO DA SAÚDE E IMPACTOS PARA A PSICOLOGIA
}

\author{
Laura Belluzzo de Campos Silva*
}

\begin{abstract}
RESUMO. No final do século XX a discussão sobre promoção da saúde foi retomada em uma série de Conferências Internacionais sobre Saúde que ocorreram no Canadá, Estados Unidos e países da Europa Ocidental. Por essas conferências, o conceito de promoção da saúde, até então considerado um dos níveis de prevenção primária, se expandiu, ampliando a concepção do processo saúde-doença e de seus determinantes, propondo a articulação de saberes técnicos e populares e a mobilização de recursos institucionais e comunitários, públicos e privados para seu enfrentamento e resolução. À reformulação do conceito correspondem mudanças epistemológicas, políticas e técnicas em diferentes saberes e profissões. O objetivo deste trabalho é apontar alguns desses impactos para a Psicologia.
\end{abstract}

Palavras-chave: Psicologia; promoção da saúde; Foucault.

\section{CHANGES IN THE HEALTH FIELD AND IMPACTS ON PSYCHOLOGY}

\begin{abstract}
In the late twentieth century, the discussion about health promotion was resumed in a series of International Health Conferences which took place in Canada, The United States and West Europe. From these conferences, the concept of health promotion, hitherto considered as one of the primary levels of prevention, expanded the conception of health-disease process as well as its determinants. It was also proposed not only the link technical and popular knowledge, but also the mobilization of institution and community resources, both public and private, for its confrontation and resolution. To the reformulation of the concept corresponds epistemological, political and technical changes, in different kinds of knowledge and professions. The goal of this work is to point out some of these impacts on psychology.
\end{abstract}

Key words: Psychology; health promotion; Foucault.

\section{CAMBIOS EN EL ÁREA DE LA SALUD E IMPACTOS PARA LA PSICOLOGÍA}

RESUMEN. Al final del siglo XX la discusión sobre promoción de la salud se ha reanudado en una serie de Conferencias Internacionales sobre Salud que tuvieron lugar en Canadá, Estados Unidos y países de Europa Occidental. Desde estas conferencias, el concepto de promoción de la salud, hasta entonces considerado uno de los niveles de prevención primaria, se expandió, ampliando la concepción del proceso salud-enfermedad y de sus determinantes, proponiendo la articulación de saberes técnicos y populares y la movilización de recursos institucionales y comunitarios, públicos y privados para su enfrentamiento y resolución. A la reformulación del concepto corresponden cambios epistemológicos, políticos y técnicos en diferentes saberes y profesiones. El propósito de este trabajo es señalar algunos de esos impactos para la Psicología.

Palabras-clave: Psicología; promoción de la salud; Foucault.

Doutora em Psicologia Social pela USP, com pós-doutorado em Psicologia Clínica pela PUC-SP. Docente do curso de Psicologia do Centro Universitário Paulistano. 
Mudanças ocorridas no campo da saúde, a partir da década de 1970, colocam para a Psicologia questões de caráter epistemológico, político e técnico: de que modo as mudanças no conceito de promoção de saúde afetam a Psicologia enquanto ciência? Que papel político desempenha a Psicologia nesse novo contexto? Que novas atribuições essas mudanças vêm exigindo da Psicologia, enquanto profissão?

Nos meados da década de 1970, nos países do primeiro mundo, os sistemas de saúde passam a ser fortemente questionados, em função da acentuada medicalização na sociedade e no próprio sistema e dos custos crescentes da assistência médica, que não correspondiam a resultados igualmente significativos. Esse questionamento deu origem ao moderno movimento de promoção da saúde, que teve início no Canadá em maio de 1974, com a divulgação do documento "A new perspective on the health of canadians", também conhecido como Informe Lalonde.

Segundo Buss:

\begin{abstract}
A motivação central do Informe Lalonde parece ter sido política, técnica e econômica, pois visava a enfrentar os custos crescentes da assistência médica ao mesmo tempo em que se apoiava no questionamento da abordagem exclusivamente médica para as doenças crônicas devido aos resultados pouco significativos que aquela apresentava (2003, p. 22).
\end{abstract}

Os fundamentos do Informe Lalonde se centram no campo da saúde, que reúne quatro determinantes: biologia humana, ambiente, estilos de vida e organização da assistência à saúde. $\mathrm{O}$ estudo conclui ainda que todos os esforços feitos até então pela sociedade para a melhoria da saúde se concentraram na organização da assistência médica, quando, na realidade, as principais causas de morbimortalidade dos canadenses residiam nos três primeiros. Para abordar os problemas do campo da saúde foram propostas cinco estratégias: promoção da saúde; regulação, eficiência da assistência médica, pesquisa e fixação de objetivos. Pela divulgação do Informe Lalonde, o movimento de promoção da saúde se ampliou, e foi realizada uma série de conferências internacionais que tiveram papel fundamental no desenvolvimento de conceitos e práticas no campo da saúde. Dentre estes eventos, um dos mais significativos foi a I Conferência Internacional sobre Cuidados Primários de Saúde, que se realizou em Alma-Ata/Canadá, em 1978, pelo alcance que teve em quase todos os sistemas de saúde do mundo.

Em 1986, por ocasião da I Conferência Internacional sobre Promoção da Saúde, ocorrida no
Canadá, foi divulgada a Carta de Otawa, documento que é considerado o termo de referência básica para o conceito de promoção de saúde em todo o mundo, que o define como: "o processo de capacitação da comunidade para atuar na melhoria da sua qualidade de vida e saúde, incluindo uma maior participação no controle desse processo" (Brasil, 2002, p. 19, citado por Buss, 2003, p. 25).

É importante ressaltar que, embora o termo "promoção da saúde" foi inicialmente utilizado para caracterizar um nível de atenção da medicina preventiva, seu significado foi sendo modificado, passando a representar, mais recentemente, um enfoque político e técnico do processo saúde-doençacuidado:

Partindo de uma concepção ampla do processo-saúde-doença e de seus determinantes, a promoção da saúde propõe a articulação de saberes técnicos e populares e a mobilização de recursos institucionais e comunitários, públicos e privados para seu enfrentamento e resolução (Buss, 2003, p. $15)$.

Desse modo, resgata-se a perspectiva de relacionar saúde e condições de vida, ressaltando-se o quanto múltiplos elementos - físicos, psicológicos e sociais - estão vinculados à conquista de uma vida saudável, destacando-se a importância tanto do desenvolvimento da participação coletiva, quanto de habilidades individuais. $\mathrm{Na}$ realidade atual, o movimento de promoção da saúde traduz-se em: políticas públicas saudáveis, colaboração intersetorial e desenvolvimento sustentável.

Atualmente, decorridos mais de 25 anos da divulgação da Carta de Otawa, este termo está associado a um conjunto de valores: vida, solidariedade, equidade, democracia, cidadania, desenvolvimento, participação e parceria, entre outros. Refere-se também a uma combinação de estratégias que envolvem: ações do estado (políticas públicas saudáveis), da comunidade (reforço da ação comunitária), de indivíduos (desenvolvimento de habilidades pessoais) e de parcerias intersetoriais, ou seja, trabalha com a noção de responsabilização múltipla, seja pelos problemas, seja pelas soluções propostas para estes (Buss, 2003).

Do ponto de vista político, há análises críticas que apontam que, na base das proposições dessa nova saúde pública, encontram-se mudanças nas estratégias de regulação estatal, que têm como objetivo a redução do papel do Estado no financiamento das ações de saúde, enfatizando a lógica do mercado. Desse modo, estariam sendo reforçadas perspectivas de individualização que, mediante discursos que 
conclamam a autonomia, estariam, na verdade, mascarando o objetivo de delegar cada vez mais aos sujeitos e grupos sociais específicos a tarefa de cuidarem de si mesmos. Por outro lado, há autores que apontam que o discurso da promoção não é homogêneo e apresenta contradições que correspondem a interesses divergentes. Já existe uma extensa produção de trabalhos sobre o tema que torna evidente o quanto as estratégias em promoção da saúde contemplam perspectivas das mais conservadoras às mais progressistas. Segundo Czeresnia e Freitas, a medicina social, na América Latina, e a Saúde Coletiva, no Brasil, inspiradas em um movimento progressista, desenvolveram uma tradição crítica própria:

$\mathrm{O}$ resgate do pensamento médico social do século XIX ocorreu a partir da década de 70 do último século como um posicionamento científico e político que estudou as relações entre saúde e sociedade, caracterizando processos econômicos e políticos, como a origem de perfis epidemiológicos complexos, próprios a situações de intensa desigualdade (Czeresnia \& Freitas, 2003, p. 10).

É importante ressaltar que é nesse contexto que surgiu a definição da atual política de saúde pública do Brasil - o Sistema Único de Saúde (SUS) - incluído na Constituição de 1988, após um intenso debate entre forças políticas conservadoras e progressistas. Segundo Costa (2002), este debate seguiu as recomendações de um documento do Banco Mundial, datado de 1987, que apontava quatro políticas básicas visando à reforma dos sistemas de saúde nos países em desenvolvimento: cobrança aos usuários dos serviços oferecidos pelo governo; estímulo à utilização de planos privados de cobertura de riscos; utilização mais eficiente de recursos governamentais e descentralização dos serviços. Dentre essas políticas, a descentralização foi a que ganhou maior destaque, por possibilitar a convergência entre interesses das instituições estrangeiras, dos órgãos governamentais e do movimento sanitarista.

\section{IMPACTOS EPISTEMOLÓGICOS: MUDANÇAS NO OBJETO DA PSICOLOGIA}

Do ponto de vista epistemológico, a discussão do conceito de promoção de saúde tem como ponto de partida o próprio conceito de saúde que, para ser ampliado, necessita de uma abordagem da ordem da complexidade, de uma perspectiva transdisciplinar, o que conclama as diversas disciplinas e áreas do saber relacionadas ao campo da saúde a deslocamentos e novos posicionamentos. No caso da Psicologia, uma inflexão significativa é o surgimento do campo de estudos e práticas que se convencionou denominar de Psicologia da Saúde. A título de exemplo das modificações significativas que essas mudanças vêm exercendo no objeto tradicional da Psicologia, tomamos as contribuições de dois autores de Língua Portuguesa reconhecidos neste campo: Pais Ribeiro e Spink. De perspectivas teóricas diferentes, ambos os autores historiam o surgimento da especialidade "Psicologia da Saúde" problematizando-a; definem as fronteiras do campo de saber delimitado pelos termos "psicologia e saúde" e, respectivamente, propõem novas interfaces entre o somático e o psíquico e entre o psíquico e o social. Pais Ribeiro (1998) afirma que, ao adotar o título Psicologia e Saúde para sua obra, pretende se distanciar da psicologia que se dedicava apenas ao diagnóstico de doenças mentais ou ao ajustamento no campo da saúde mental. O autor afirma ainda que pretende ultrapassar a especialidade Psicologia da Saúde, que se aplicava às doenças físicas, tal como ficou expressa no relatório, publicado em 1976, pelo grupo que deu início a essa especialidade. A intenção do autor nesta obra é a de ultrapassar a "dicotomia corpo espírito inerente à intervenção tradicional que se faz no campo da saúde" (Pais Ribeiro, 1998, p. 14). Para proceder a essa ultrapassagem, o autor recorre ao paradigma ecológico, que tem raízes na biologia, tomado como quadro de referência que facilita a compreensão da natureza das relações das pessoas com o seu meio físico e sociocultural, adotando, portanto, uma perspectiva ecológica da saúde e da promoção da saúde.

Já Spink, ao historiar as diferentes contribuições teóricas no campo da Psicologia da Saúde que visam incorporar a dimensão social ao processo saúdedoença, constata que a maior parte delas está impregnada de uma visão individualista, reflexo da situação em que se encontrava a própria Psicologia por ocasião do surgimento desta especialidade:

Se o viés individualista perpassa toda a psicologia, perpassando até mesmo várias vertentes da psicologia social - a disciplina mais fronteiriça com as demais ciências sociais -, como não haveria de influenciar a psicologia da saúde que se consolidava nos anos 70 e 80! As principais teorias da psicologia da saúde são uma mistura de teorias da psicologia social e cognitiva desenvolvidas no período de 1950 a 1980. $\mathrm{Ou}$, como veremos a seguir, são derivativas da psicologia clínica, também ela, até muito recentemente, de cunho eminentemente individualista (Spink, 2003, p. 69). 
Visando ampliar esse enfoque, a autora propõe que se ressignifique o próprio conceito do que é social, pelas contribuições das novas estratégias teóricas e metodológicas filiadas às correntes construcionistas, que buscam desconstruir a dicotomia entre estados individuais e comportamentos, passando a entender todas as manifestações das subjetividades como práticas sociais. Nesse sentido, a autora afirma que os esforços de suas pesquisas vêm buscando "entender o sentido dos eventos relacionados com saúde e doença a partir da análise das práticas discursivas; práticas estas essencialmente entendidas como manifestações da sociabilidade" (Spink, 2003, p. 73).

Nos dois casos, podemos vislumbrar o risco de um reducionismo em que, paradoxalmente, na tentativa de ampliar o objeto de estudo da Psicologia para o campo da saúde, a própria Psicologia parece sair diminuída. Em outras palavras: no primeiro caso, de uma Psicologia criada para tratar da mente de um indivíduo - passamos para uma psicologia que cuida da integração mente-corpo - sem, no entanto, ficar claro como se deu tal integração. No segundo - para escapar de uma psicologia individualista, corre-se o risco de reduzir as questões de saúde e doença a meros efeitos de práticas discursivas.

\section{IMPACTOS POLÍTICOS: DOS CORPOS DÉCEIS AOS CORPOS SAUDÁVEIS}

Para que possamos compreender os impactos políticos que as modificações no campo da saúde exercem sobre a Psicologia é preciso estabelecer relações entre Psicologia e poder. Segundo Foucault (1983), a Psicologia, enquanto discurso e prática social, se instaura na sociedade disciplinar, como um saber cujo objeto é a alma, tendo como incumbência gerenciar as práticas de normatização. $O$ poder ostensivo que até então era exercido pelo soberano é substituído por micropoderes capazes de abranger e atingir até o mais fino grão da sociedade, sendo aplicado ao nível dos indivíduos, dos corpos, dos gestos e dos comportamentos. A história desta microfísica do poder punitivo seria então uma genealogia ou uma peça para uma genealogia da alma moderna na qual podemos reconhecer o correlativo atual de certa tecnologia do poder sobre o corpo: "Alma que, diferentemente da alma representada pela teologia cristã, não nasce faltosa e merecedora de castigo, mas nasce antes de procedimentos de punição, vigilância, de castigo e de coação" (Foucault, 1983, p. 31). Sobre essa realidade referência foram construídos vários conceitos e campos de análise: psique, subjetividade, personalidade, consciência etc. Para Foucault, as práticas psi "tradicionais" se fundam em diferentes objetos: alma, psique, subjetividade, personalidade, comportamento etc. que se prestam, em maior ou menor grau, como coadjuvantes das práticas disciplinares. Sucedendo as práticas higienistas e normalizadoras, que inicialmente coube à medicina realizar, doravante cabe à Psicologia agir sobre a superfície anímica recém-criada sobre o corpo, possibilitando que o domínio deste se faça por intermédio de uma disciplinarização, que dociliza os corpos tornando-os, ao mesmo tempo, mais obedientes e mais úteis. Mas, se é em nome da humanização dos castigos que se justifica tal mudança, não devemos nos enganar, diz Foucault, pois o homem de que nos falam não é o homem liberto, e sim o homem já efeito de uma sujeição mais profunda. Um homem em quem habita uma alma que é ela mesma uma peça no domínio exercido pelo poder sobre o corpo. Em "A vontade de saber" (1997), Foucault retoma a ideia de que, a partir do século XVIII, surgem mecanismos de poder extremamente novos, que tomam a vida do homem na qualidade de corpo vivo e que funcionam não pela lei, mas pela normalização. Não pelo castigo, mas pelo controle, demonstrando como o poder consegue chegar até às mais tênues e individuais das condutas - a sexualidade.

Mas a sociedade disciplinar que Foucault descreveu está ficando para trás. Deleuze (1992) afirma que Foucault foi um dos primeiros a apontar que já não estamos na sociedade disciplinar, mas na sociedade de controle, que funciona não por confinamento, mas por controle contínuo e comunicação instantânea. Cabe então indagar: "Se na sociedade disciplinar o controle social se efetivava sobre os corpos por meio da alma, necessitando para isso de uma Psicologia, como se exerce o controle na sociedade atual e por que meios?

Bruno (1997) e Moraes e Nascimento (2002) apontam que estamos passando do controle social pautado pelo exercício da norma da sociedade disciplinar para o imperativo da antecipação do risco da sociedade de controle. Segundo Sfez (1996), uma das explicações para essas mudanças é a decepção com o fim das grandes narrativas - que por sua vez ocasionou a falência do antigo modo de subjetivação que remetia ao desejo como forma de libertação do indivíduo. Resta então, como lugar que resiste, o corpo - sendo nele que agora se deve operar mudanças que visam torná-lo mais saudável, prevenir doenças e aumentar a longevidade. Um dos efeitos mais imediatos disso é que o controle social que até então vinha sendo exercido pelas Ciências Humanas está sendo paulatinamente delegado para o saber que advém das neurociências, da biotecnologia e da epidemiologia de riscos. Ao encontro das colocações de Sfez, Birman (1999) defende que a possibilidade de 
transformar a si próprio a partir do desejo - promessa da Psicanálise - foi tirada dela, pois a ideia de que o mundo poderia sempre ser reinventado pelo sujeito foi enterrada. O modo de subjetivação dominante se opõe ao que foi proposto pela Psicanálise, pois na pósmodernidade perde-se a crença de que o desejo seria a condição de reinvenção do sujeito, as culturas do narcisismo e do espetáculo construíram um modelo de subjetividade em que se silenciam as possibilidades de reinvenção do sujeito e do mundo. Além disso, para Birman (1999), razões intrínsecas à própria Psicanálise teriam concorrido para que esta estivesse sendo substituída por outras tecnologias: a ênfase excessiva nos registros da linguagem e do pensamento, deixando o corpo e os afetos de lado e a perda de seu poder crítico. Com a decepção produzida pela promessa ilusória da Psicanálise, outros prestidigitadores ocuparam o lugar deixado por ela, relançando as mesmas promessas.

\section{IMPACTOS TÉCNICOS: MUDANÇAS NA PRÁTICA PROFISSIONAL DOS PSICÓLOGOS}

No que se refere à prática profissional, constata-se uma ampliação expressiva do campo de atuação do psicólogo na área da Saúde, não mais restrito ao estudo e intervenção no campo da saúde mental. Atualmente, fazem parte do campo de ação do psicólogo, intervenções que compreendem desde as práticas preventivas de educação em saúde até o assessoramento nos procedimentos médicos mais inovadores e complexos como cirurgias bariátricas, transplantes de órgãos e técnicas de procriação artificial.

\section{CONSIDERAÇÕES FINAIS}

As mudanças que ocorreram no campo da saúde, nas últimas décadas do século $\mathrm{XX}$, provocam impactos significativos para a Psicologia. Do ponto de vista epistemológico, conclui-se que a Psicologia da Saúde não é suficiente para fundamentar com clareza a mudança no objeto da Psicologia requerida por tais mudanças. Do ponto de vista político, constata-se que à medida que a superfície anímica se estreita e que o corpo biológico passa a ser o novo alvo de dominação política, a Psicologia deixa de exercer o poder normatizador que exercia e passa a atuar na prevenção de riscos e em novas práticas de saúde.

\section{REFERÊNCIAS}

Birman, J. (1999). Mal estar na atualidade: a psicanálise $e$ as novas formas de subjetivação. Rio de Janeiro: Civilização Brasileira.

Bruno, F. (1997). Do sexual ao virtual. São Paulo: Unimarco.

Buss, P. (2003). Uma introdução ao conceito de promoção da saúde. In: Czeresnia, D. e Freitas, C. M. (Orgs.). Promoção da saúde: conceitos, reflexões, tendências. (pp. 15-37). Rio de Janeiro: Fiocruz.

Costa, R. R. (2002, junho). Descentralização, financiamento e regulação: a reforma do sistema público de saúde no Brasil durante a década de 1990. Revista de Sociologia e Política, 18, 49-71.

Czeresnia, D., \& Freitas, C. M. (2003). Apresentação. In Czeresnia, D., \& Freitas, C. M (Orgs.) Promoção da saúde: conceitos, reflexões, tendências. (pp. 9-14). Rio de Janeiro: Fiocruz.

Deleuze, G. (1992). Controle e devir. In Deleuze, G. Conversações. (pp. 209-218). Rio de Janeiro: Ed. 34

Foucault, M. (1983). Vigiar e Punir: nascimento da prisão. (2a ed.) Petrópolis: Vozes.

Foucault, M. (1997). História da sexualidade 1: A vontade de saber. (12a ed.) Rio de Janeiro: Graal.

Moraes, T. D., \& Nascimento, M. L. (2002, janeiro e junho). Da norma ao risco: transformações na produção de subjetividades contemporâneas. Psicologia em Estudo, 7(1), 91-102.

Pais Ribeiro, J. L. (1998). A psicologia no campo da saúde. In Pais Ribeiro, J. L. Psicologia e Saúde. (pp. 31 a 102). Lisboa: ISPA.

Sfez, L. (1996). A saúde perfeita: crítica de uma nova utopia. São Paulo: Loyola.

Spink, M. J. (2003). Psicologia social e saúde: construindo saberes. In Spink, M. J. Psicologia social e saúde: práticas, saberes e sentidos. (pp. 19-76). Petrópolis: Vozes.
Endereço para correspondência:
Laura Belluzzo de Campos Silva - Rua Demóstenes 636, apto. 52. Campo Belo - CEP: 04614013, São Paulo-SP, Brasil. E-mail: laurabelluzzo@yahoo.com.br. 